\title{
Insights in costing of continuous broadband internet on trains to allow delivering value via services.
}

\author{
Bram Naudts, Jan Van Ooteghem, Sofie Verbrugge, Didier Colle, Mario Pickavet \\ Dept. of Information Technology (INTEC) \\ Ghent University - iMinds, Ghent, Belgium \\ Email: \{bram.naudts, jan.vanooteghem, sofie.verbrugge, didier.colle, mario.pickavet\}@intec.ugent.be
}

\begin{abstract}
Continuous broadband Internet on trains is at the moment being deployed worldwide but not always profitable. Solely providing internet for travellers will have a negative return on investment. But, different service providers could be interested to share the unused capacity of resources deployed to offer other services. In this way, resources and their costs are shared over several services and revenues may rise above the total cost. Service operators should therefore be able to make well informed decisions based on an ex-ante estimate of the cost of a service. Using activity based costing (ABC), we investigate on the one hand how to determine the total cost of resources supplied and on the other how to estimate the cost of consumed resources of a service.

Our results show that $\mathrm{ABC}$ can adequately cope with the case specific nature of the rollout of services on a train. $\mathrm{ABC}$ provides insights in the contributors to the cost per service and the unused capacity. Moreover, obtained results can be used to distribute the cost based on the usage of resources, activities and services, evaluate the service mix and identify candidates for outsourcing. Still, ABC does not give insight in how the unused capacity of a resource should be allocated. The optimal allocation of unused capacity will therefore remain the focus of future work.
\end{abstract}

\section{INTRODUCING INTERNET ON TRAINS}

People increasingly expect to be able to get on internet independent of location. Internet access is increasingly becoming available on trains. In 2005, Thalys, a European train operating company (TOC) operating high-speed trains between Paris, Brussels, Amsterdam and Cologne, started with an offering of on-board broadband internet. Nederlandse Spoorwegen (NS), a Dutch government owned TOC, started tests with on-board broadband internet in 2005. In 2011 the service has been rolled out in the 100th train. NS claims that by 2013 all of its trains will be equiped with Wi-Fi hotspots. In 2011, the Bejing-Shanghai high-speed railway started the rollout of high speed Internet for commuters and in 2013, Indian Railways, has launched a pilot project to install a free Wi-Fi service in passenger trains in the country. Travellers taking the Eurostar will be able to use Wi-Fi to surf the Internet onboard from early 2013. Many other rollouts have been completed or are being planned.

According to [1], providing Internet access to passengers on-board trains makes good business sense: Internet access for passengers can provide a revenue stream for the train company while attracting more travelers. But, one of the conclusions from a previous techno-economic investigation [2] is that solely providing support for Internet on-board for travellers will have a negative return on investment.
This has several reasons. First, according to [3] a passenger Internet service on trains does not appeal to a mass market but will attract a rather limited but heavily interested niche. The willingness to pay is low because Internet is more and more considered as an expected amenity. Second, the deployment and operation of Internet services on trains is expensive.

But, service operators show interest in offering services on trains that use the same resources that are deployed for providing Internet for passengers. These resources are seldom fully utilized and as such have free capacity that can be used by other services. By allowing service providers to use the equipment deployed for providing Internet on-board for travellers the resources can be leveraged to offer other services. In this way, investments are spread over several services and the overall revenues may rise above the total cost.

The main research questions we want to answer in this paper are how to determine the total cost of the resources provided and how to obtain the cost of resource consumption when offering Internet services on trains. The difference between the total cost and the cost of resource consumption of the service mix is illustrated by this relationship: total cost $=$ cost of resource consumption of a service + unused resources. The unused resources can be used to offer other services without increasing the total cost.

The outcome is valuable for providers of network resources that apply cost-based pricing, for service providers to evaluate if the willingness to pay for their service is large enough to cover the cost of the service and for decision makers to optimize the service mix.

The problem of obtaining the costs related to a service is not a self-defined one. In order to define the cost level in a significant way we start by describing the methodology in section II. Section III introduces a case study that will be used throughout the paper to further clarify the proposed approach.

The paper is further structured according to the consecutive steps to determine costs. An overview of the flow of this paper is provided in figure 1. Section IV describes the predominant network architecture that is used to rollout Internet services on-board a train. Section V defines the demand for the service to be provided. The inputs from sections IV and $\mathrm{V}$ feed the dimensioning process described in section VI. Dimensioning rules are used to derive the bill of material. At the end of the dimensioning process, components are calculated and every component's cost is estimated. By summing up the annual 


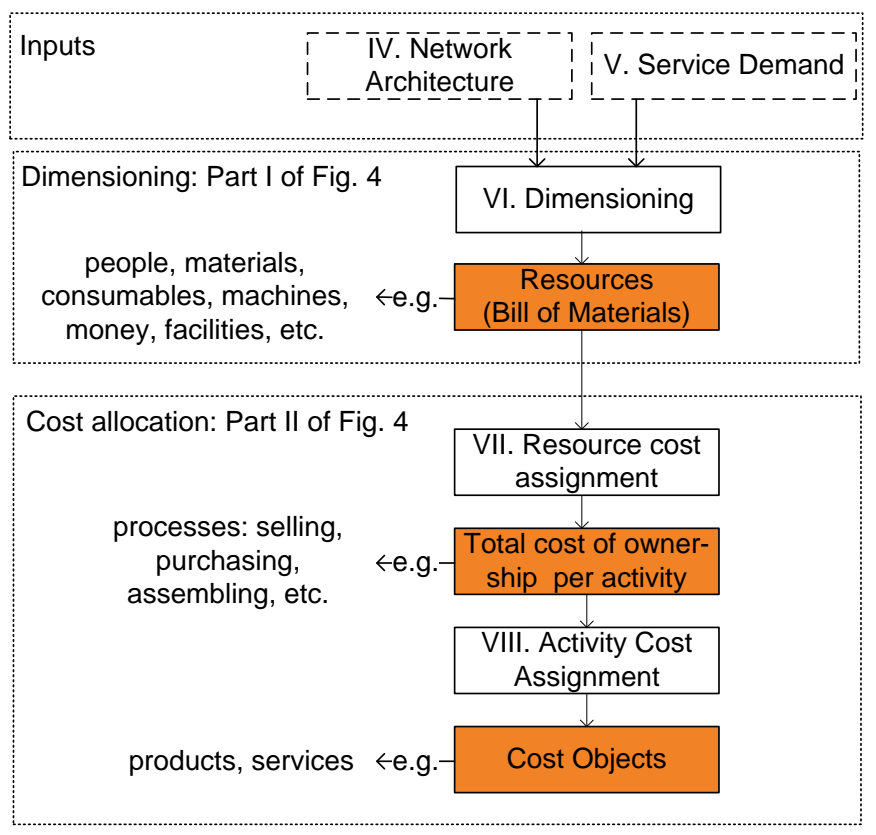

Fig. 1. Stepwise overview of input gathering, dimensioning, cost assignment and cost allocation.

costs of all activities the total annual cost is obtained.

In section VII resources are grouped into activities and an activity driver is identified to derive the cost per activity. To allocate the resource cost to the demand originating it, in section VIII the activity usage of a service is determined based on the service demand from section V. The cost of consumed resources of a service is then obtained by summing up the costs allocated to a service.

Our conclusions are discussed in section IX.

\section{Methodology}

Costs are obtained through a bottom-up approach to support an ex-ante investment decision. Application of the bottomup model requires determining the demand for services as starting point, to adopt an appropriate network to serve the demand, and then aggregating the cost in a structured manner to determine the total cost. Once the cost centres have been determined, the service cost is ready to be obtained [4]. This step consists in allocating the costs that are incurred in the production of an activity across all services. We will now discuss Activity Based Costing ( $\mathrm{ABC}$ ) as a costing procedure with a focus on the way $\mathrm{ABC}$ is used to allocate costs.

A costing procedure starts with estimating the cost of resources and the identification of the activities that use those resources. The costs of the resources are then allocated to the costs of the activities. In order to deal with costs and their different nature, a cost definition is introduced which indicates the way a service consumes resources. Three categories are used: common costs are used for the production of any service, joint costs are used by a subset of the services and a dedicated cost is directly related to a service. In the next step costs have to be allocated to services.
$\mathrm{ABC}$ will only allocate the cost of a used resource to a service and put the unused resources aside. This is illustrated in an example. The annual TCO of a storage server with 2000 Gigabyte (GB) of storage capacity is estimated at $€ 1000$ and is used by two services (joint cost). The first service and the second service use respectively 200 and 300 GB of storage space. In traditional costing the cost per GB will be estimated as the total cost divided by the total usage, i.e. $€ 1000 /(200+300)=€ 2 / \mathrm{GB}$ and respectively $€ 400$ and $€ 600$ will be allocated to the first and second service. ABC takes the capacity of a resource/activity into account. In ABC the cost per GB will be estimated as the total cost divided by the available capacity, i.e. $€ 1000 / 2000=€ 0.5 / \mathrm{GB}$ and respectively $€ 100$ and $€ 150$ will be allocated to the first and second service, the remaining capacity is considered as unused capacity and can be used by other services without increasing the total cost.

Our goal is to find the total cost, the cost of resource consumption of a service and the unused capacity through activity based costing.

\section{CASE STUDY}

To illustrate the proposed approach we will consider a case in which a train operating company is planning to offer Internet services on-board its fleet. The services will be introduced on the train line Oostende-Eupen in Belgium. Each train will be refurbished and during the refurbishment the cabling can be placed in the floors and roofs for an on-board network. A single trip from Oostende to Eupen takes 181 minutes, trains leave the station every hour and 8 different trains are used to operate this route. Each train is composed of a single locomotive, 11 passenger cars and a single cab car and can carry 878 passengers.

\section{Network ARChitecture}

A network architecture is required to start the dimensioning process of the on-board network. Several network architectures are possible to provide wireless train-to-wayside data services. The predominant network architecture as described in [5] routes the data traffic from an on-board access point towards a central authority (an integrator) before going to its final destination. Multiple technologies and/or network operators are typically used within this scenario. Different mobile networks (GPRS, UMTS, HSDPA and LTE) are combined to set up an Internet connection to the train without extra Capital Expenditures (CapEx) investments or new deployments if possible. A dedicated wireless data network (Wi-Fi, WiMAX) can be rolled out when the available mobile networks are no longer able to cope with the requested bandwidth. This requires a large investment involved in the installation of the network infrastructure. A last, expensive solution that covers a wide area is to set up a connection with a satellite. The drawback of this technology is that a clear line-of-sight is required [2], [6]. Each train is equipped with one or multiple heterogeneous network interfaces. The network for connecting the trains with the wayside is star-shaped (with an integrator 
as central node) and consists of Internet Protocol (IP) based network tunnels over each radio access network toward each train. These IP tunnels are combined and terminated on the train's access router and the integrator's wayside router, such that the individual radio access networks remain transparent for the outside world. Data traffic is forwarded in the tunnel from the train to the integrator and the integrator forwards this traffic to its final destination at the wayside. Typically, the tunneling protocol is proprietary and requires dedicated hardware in the central management system and on-board the train. For clarification, the complete architecture is schematized in Figure 2 [5].

For the train line considered (Oostende-Eupen) the train operating company will use the available Wi-Fi hotspots in stations and the available mobile network of the cellular operators. The train spends about $10 \%$ of the journey time in a station where Wi-Fi is available, the remaining $90 \%$ is covered by the mobile network of the cellular operators.

\section{DEMAND OF SERVICES}

Services can be categorized in four distinct categories, pure passenger internet, passenger comfort services, safety and security related applications and cost saving applications. These are discussed in more detail in [7].

The train operator considered in this paper is interested in offering three services on the train line Oostende-Eupen. Onboard Wi-Fi, passenger infotainment and Video-on-Demand (VoD). Each of these services will be provided to the passengers on their own connected device. A VoD service with movies is especially interesting for long distance trajectories. To attract customers who spend less time on the train, the train operator will also offer shorter multimedia fragments such as TV-shows (typically between 20 and 40 minutes).

Application of the bottom-up model requires referring to the demand of services as starting point to adopt an appropriate network to serve the demand. It is defined in terms of customers, traffic, storage, latency, etc. depending on the nature of the service.

Figure 3 defines the demand for each service in terms of customers, bandwidth and storage capacity. The values are based on discussions with industry experts that have done rollouts of similar services before. The demand in terms of customers can be estimated by using the seat occupancy and the expected adoption rate. Often peak occupancy will be used. The bandwidth for passenger Wi-Fi is estimated at 50 Kbit/s per passenger. This amount of bandwidth has to be provided by a connection both on-board the train as well as between the train and the wayside during the entire travel time. Both passenger infotainment and $\mathrm{VoD}$ store data onboard the train to limit the traffic between the train and the wayside. The infotainment service and $\mathrm{VoD}$ service do not require a continuous connection to the wayside. New content can be uploaded at specific locations where cheap bandwidth is available. Examples are stations and depots equipped with Wi-Fi.

\begin{tabular}{l|l|c|c|c} 
service & description & adoption & bandwidth & storage \\
\hline \hline $\begin{array}{l}\text { passenger } \\
\mathrm{Wi}-\mathrm{Fi}\end{array}$ & $\begin{array}{l}\text { web browsing and email, } \\
\text { no large files, via own } \\
\text { devices }\end{array}$ & $30 \%$ & $50 \mathrm{Kbit} / \mathrm{s}$ & $0 \mathrm{~GB}$ \\
\hline $\begin{array}{l}\text { infotain- } \\
\text { ment } \\
\text { portal }\end{array}$ & $\begin{array}{l}\text { real time travel } \\
\text { information, information } \\
\text { about train operator } \\
\text { services, via own devices }\end{array}$ & $10 \%$ & $50 \mathrm{Kbit} / \mathrm{s}$ & $20 \mathrm{~GB}$ \\
\hline $\begin{array}{l}\text { video-on- } \\
\text { demand }\end{array}$ & $\begin{array}{l}\text { movies and tv-shows, via } \\
\text { own devices }\end{array}$ & $5 \%$ & $1 \mathrm{Mbit} / \mathrm{s}$ & $380 \mathrm{~GB}$
\end{tabular}

Fig. 3. List of services to be offered on the train line Oostende-Eupen completed with technical specifications. The demand per service will drive the dimensioning- and cost allocation process.

Still other inputs can be required to determine the demand originating from services, i.e. a voice over IP service may have specific requirements such as low latency or a guaranteed amount of bandwidth while other services may require extra or redundant equipment to handle deviations from the normal mode of operation (resiliency). These inputs need to be sufficient to feed the dimensioning process that follows.

\section{Dimensioning}

With both network architecture and service demand available the dimensioning process can start. The bottom-up model uses a two step approach. First, the network architecture together with the dimensioning rules are used to derive the network elements. Second, the specific network elements (such as routers, switches, access points, etc. ) that are used to provide a service are dimensioned.

The required network elements are divided in four areas as already indicated in Figure 2: in train-, train to wayside, integrator- and wayside infrastructure. The connection to the wayside uses an on roof antenna system consisting of the antenna itself, a signal splitter and radios that receive and transmit the signal. Coaxial cables interconnect the roof antenna system with the on-board equipment. The in train network equipment consists of an on-board gateway server which will direct the traffic from the offered services to the right destination. At the wayside, multiple technologies and/or network operators are used to connect the train to the wayside.

For the case considered, the existing cellular infrastructure and Wi-Fi access points in the stations are used to transmit and receive data signals. We assume that this combination of technologies is adequate but in reality not every area will be covered by a cellular network therefore satellite or the deployment of a dedicated Wi-Fi/WiMAX network can be considered. When deploying a dedicated solution a backhaul system is required to connect the Wi-Fi/WiMAX base stations to the core network. Depending on the selected services certain equipment has to be added to provide the service. For the services considered in the case study one option is to provide no end devices and let the passengers access the service via their own devices (e.g. laptop, smartphone or tablet), another option could be to install touch displays at every seat. The first option is pursued here. For the delivery of these services 


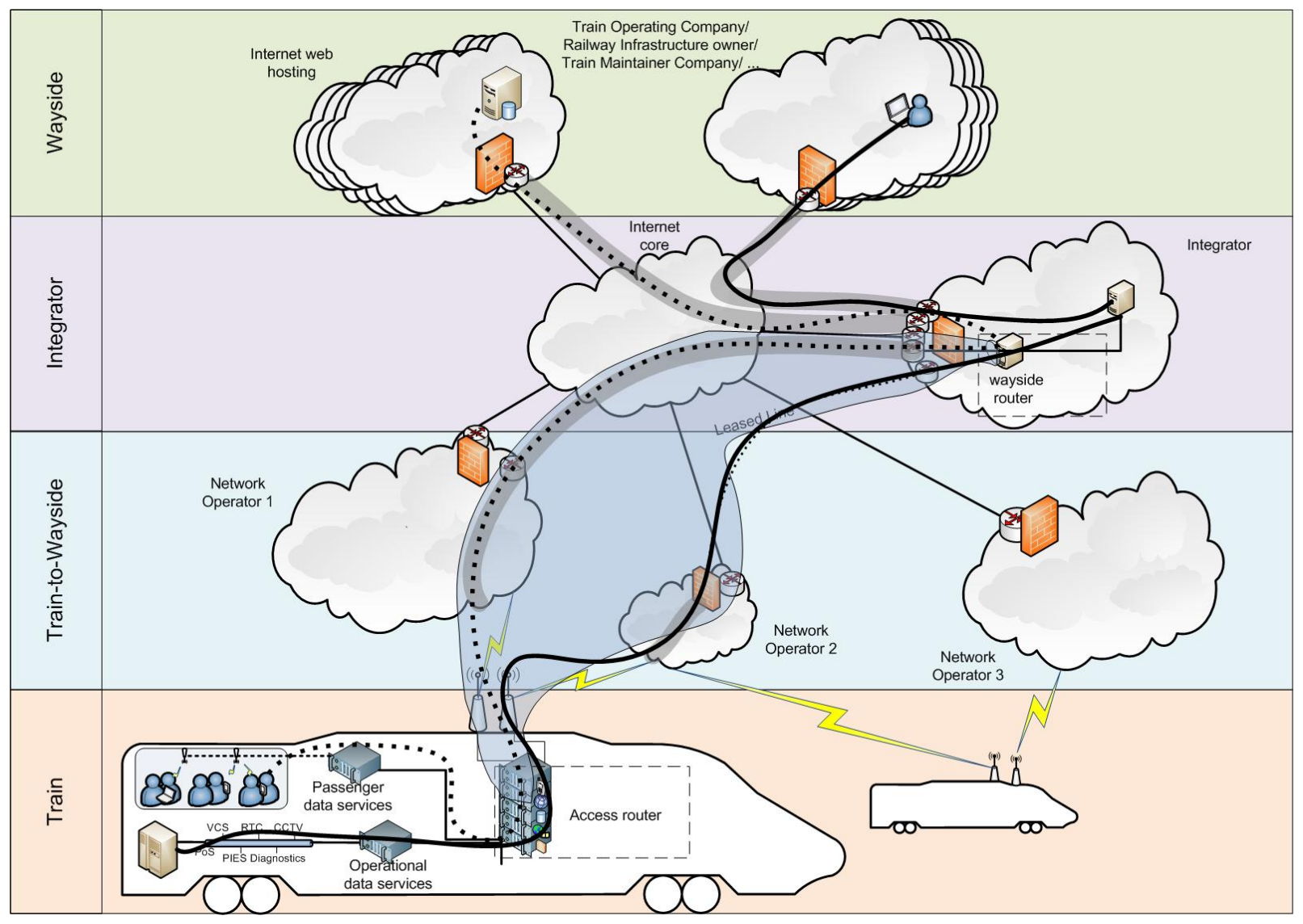

Fig. 2. A typical passenger data service flow is depicted by a dotted line, an operational data service flow in a solid line. The transparent envelope symbolizes the hiding of the Train-Integrator tunnels from the outside. There are three types of network operators that can be used to obtain the wireless link: a satellite operator, an existing mobile network operator and deploying and operating a dedicated wireless network. This architecture will be used in section VI in which the network devices will be dimensioned to construct the bill of material.

the in train network will be extended with a Wi-Fi distribution system. Wireless Access Points (WAPs) are typically attached to the ceiling of the carriages and connected via Category 5e UTP cables to the on-board servers and access routers. The infotainment service provides real-time travel information, this requires a GPS tracking system. In most cases a dedicated server will be installed for both the infotainment service and the VoD service. At the wayside the service will often be hosted in the cloud to decrease the risk of a single point of failure and a manned network- and service operations centre will be set up to provide support.

Once the components have been identified and their specifications and price is known, we need to estimate how many of each component will be required to provide the infrastructure. This happens based on dimensioning rules. We illustrate the dimensioning process for WAPs, the antenna system and the video server.

The typical number of WAPs per carriage is two but this can vary depending on the layout and length of the carriage. The number of WAPs is also dependent on the expected service demand. The threshold for a decent connection will vary according to the bandwidth demand per user. When the number of connecting passengers is above this threshold the service operator should consider adding an extra WAP. Based on expert opinion, we estimate that an industrial grade WAP can support 60 concurrent connections of $1 \mathrm{MB}$. For the case considered, 2 WAPs per rail car will be sufficient and the cost of ownership per WAP is estimated at $€ 194$ per year (or $€ 37,303$ to install WAPs on all 96 cars).

A train will typically install several antennas which each make an individual connection to the wayside. Per train 8 antennas will be installed and the cost of ownership per antenna is estimated at $€ 185$ per year (or $€ 11,851$ to install antennas on all 8 trains).

Per train, a dedicated video server will be installed for a VoD service. To avoid a single point of failure the video server will be duplicated. The type of video server is dependent on the required storage capacity and processing power to provide the service. The cost of ownership per video server is estimated at $€ 984$ per year (or $€ 15,737$ to install video servers on all 8 trains).

These examples illustrate the dimensioning process. At the end of the dimensioning process, every element's cost is evaluated based on the list price and a bill of material can be created. By including resources such as labour, space and energy, the bill of material is extended to a bill of resources. A 
pay-off policy is applied to obtain the annual cost per element.

The output of this process is a bill of resources which describes a list of activities in terms of resources. By summing up the annual cost for the resources of every activity the annual cost of the activity is obtained. For reference, an overview of the results of the dimensioning process is given in part I of Figure 4. These contain the network elements that were discussed in more detail in this section (WAPs, antennas and VoD server) as well as the other required network elements. Part II of Figure 4 will be described in more detail in sections VII and VIII.

\section{RESOURCES AND ACTIVITIES}

The first step in an activity based analysis is to estimate the expense of an activity which is covered by the bill of resources from the previous section. The second step is to estimate the number of units of service activity that can be delivered by the resources supplied. For each of these resources, the capacity is derived in terms of an activity driver.

The cost of a dedicated resource such as a VoD server is attributed entirely to a single service. The identification of an activity driver is therefore not required as the cost will be fully allocated to a single service anyway.

For shared and common resources a suitable activity driver has to be obtained. These activity drivers were derived based on discussion with industry experts. The capacity in terms of activity drivers is often dependent on the specifications of the chosen equipment. The discrepancy between the values mentioned in this paper and those in data sheets is explained by the suboptimal conditions in a train.

Per WAP, 60 connections of 1 Mbit per connection can be established, the activity driver for this resource is the number of connections used. A Cat 5e UTP cable in a train has a throughput of $100 \mathrm{Mbit} / \mathrm{s}$, the throughput is used as an activity driver. For the onboard gateway server and the antenna system the average throughput is used as activity driver. The average throughput can be calculated as follows: number of antennas $\mathrm{x}$ average bandwidth per antenna. The average bandwidth per antenna is dependent on the used networks and their availability.

At the wayside, network and service support is provided. A duo of network engineers can support around 20 trains and 5 different services. A special case are the wayside content creation server, the management server and the wayside gateway server which are hosted in the cloud. Cloud servers are paid for based on their usage and resources are supplied as needed. The required storage capacity is used as an activity driver.

For the train-to-wayside connection the cost of Wi-Fi is considered as negligable, usage of the cellular infrastructure is charged per packet of $2 \mathrm{~GB}$ by the network operator to the service provider and supplied as needed.

These activity drivers can be found in the first column of part II of Fig. 4. This activity driver will be used in the next section to allocate the costs of a resouce to a service based on the amount of activities (or resources) a service consumes.

\section{DEMAND-RELATED COST}

In the last step the activities are identified that are used to deliver services. The costs of those activities are allocated to each service. To allocate costs, the usage in terms of activity drivers is estimated and the proper proportion of costs is attributed to the service. The application of this costing methodology allows obtaining accurate cost estimates.

With 5\% adoption of the VoD service (figure 3) and assuming a fully booked train 44 passengers will use the service at the same time on average. With a total of 12 cars, 4 connections per car will be consumed by the VoD service. Because a total of 60 connections are available and 4 are used by this service, a proportionate share will be allocated to the cost of this service $(4 / 60$ of $€ 37,303)$. This is illustrated in the columns labeled with services in part II of Fig. 4. A video stream has a demand of $1 \mathrm{MB}$ per second per passenger for the internal network (WAPs and wiring) and no demand for the train-to-wayside network because the content is stored on-board and updates of the movie catalogue are done over Wi-Fi (which is considered free). The VoD service also uses a dedicated VoD server which is fully allocated to the service. The usage of the wayside servers is based on the required storage capacity (another option would have been the processing power). A similar type of calculation can be done for the passenger Internet and passenger infotainment services and the right share of costs is allocated to each of the three services. The outcome is illustrated in part II of Figure 4.

Using this costing methodology we have obtained the total cost of offering Internet on-board of trains as well as the cost per service. This is on itself a means to an end. The goal is to increase profits. The ABC statement (figure 4) can be used to (re)price services or to change the service mix when the revenue received does not exceed the costs of resources used to produce the service. Once this situation is discovered the price of a service can be raised. Raising the price may in many cases have a negative effect on the demand for the service and can as such reduce the total revenue. If the service cannot generate sufficient revenues to cover all service-specific costs the unprofitable service can be eliminated and replaced a profitable service.

The ABC statement also provides insight in the amount and cost of unused resources. We have not discussed how the cost of unused capacity should be distributed among services. Several options are available, one is to distribute the cost of unused resources among the existing services as such raising the service cost. Another is to introduce new services that consume (some of) the unused resources.

\section{CONCLUSIONS}

On-board connectivity is increasingly one of today's customers' expectations but rail operators should evaluate carefully if the investment provides an adequate return on investment as in the end they want to make a profit.

The investment in resources to provide a network and the related activities will typically leave some unused capacity 


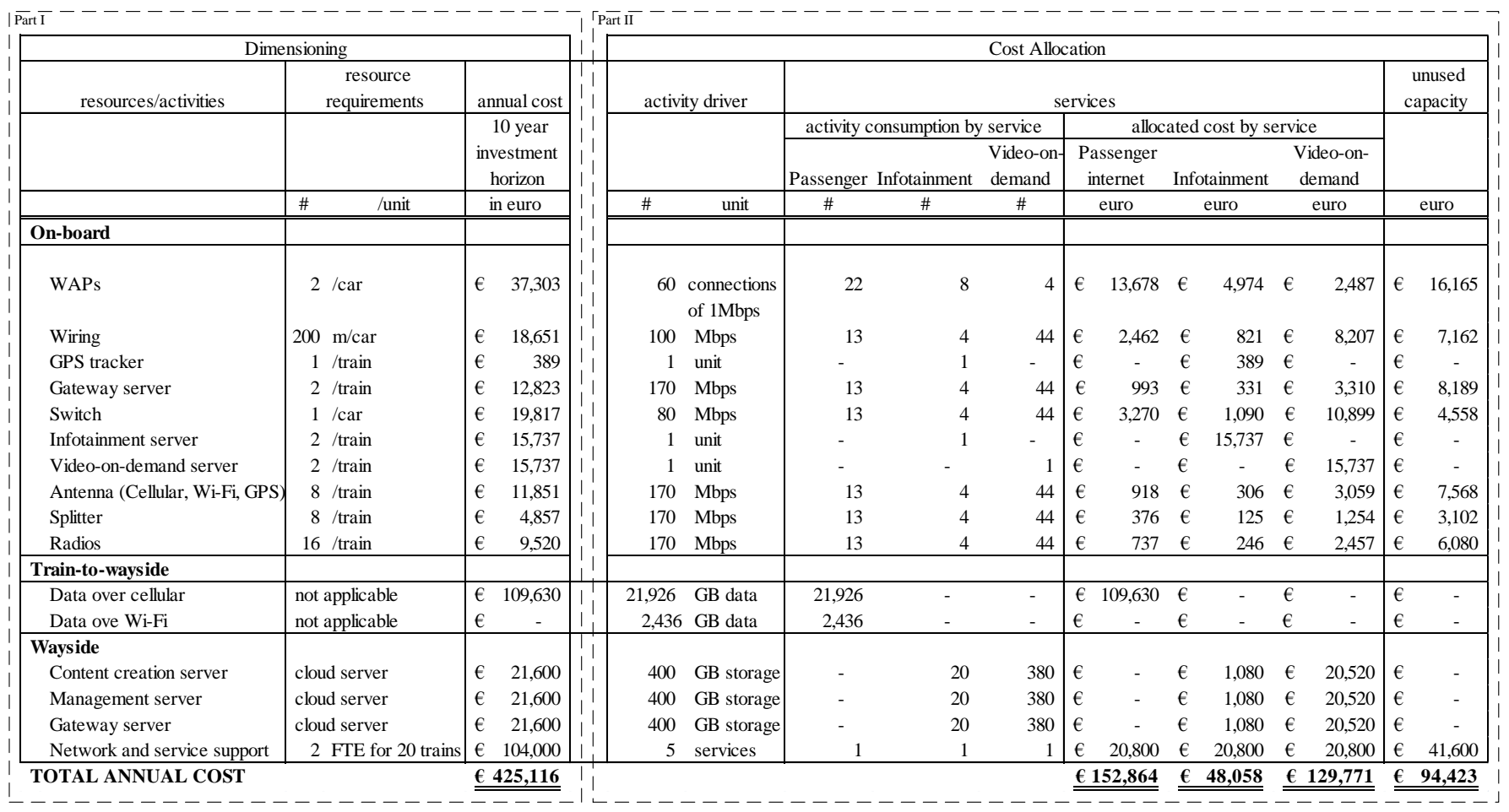

Fig. 4. Activity based costing statement for the considered case. Part I and Part II of this statement together form a ABC costing statement. The proposed services are passenger Internet, infotainment and a VoD service on the train line Oostende-Eupen. The service is rolled out on 8 different trains and each train is composed of a single locomotive, 11 passenger cars and $1 \mathrm{cab}$ car. In part I the total annual cost is obtained. In part II the costs are allocated to specific services based on their activity consumption. Both the cost of resource consumption of a service and cost of unused capacity are obtained.

which should not be fully allocated to a service because it can be used to offer additional services.

To solve this problem we have applied an activity based costing system to evaluate the cost of Internet on trains. Our results show that this costing method can adequately cope with the case specific nature of the rollout of Internet services on-board a train and provides detailed insights in the main contributors to the cost per service and the unused capacity. Moreover, the obtained results can be used to price usage of resources, activities and services, alter the service mix when the revenue received do not exceed the costs of resources and activities and identify candidates for outsourcing when an activity is largely unused or the activity can be procured else at a better price or at better quality.

The drawback of the proposed costing system is the difficulty to allocate resources to activities and activities to services. We have used a set of criteria and rules to overcome this drawback. These rules are based on technical specifications of network equipment or rules of thumb from experienced users. Still, finding the right set of criteria and rules is essential and will determine the reliability of the analysis.

Our work has focused on determining the total cost, the cost of consumed resources of a service and the determination of unused capacity via Activity Based Costing. Still, ABC does not give insights in how the unused capacity of a resource should be allocated. The allocation of unused capacity will therefore remain the focus of future work.

\section{ACKNOWLEDGMENT}

This research was carried out as part of the iMinds RAILS project. This project is co-funded by iMinds a research institute founded by the Flemish Government. Companies and organizations involved in the project are Televic Rail, Uify, Option and Belgacom, with project support of IWT.

\section{REFERENCES}

[1] D. Fokum and V. S. Frost, "A survey on methods for broadband internet access on trains," IEEE Communications Surveys and Tutorials, vol. 12, no. 2, pp. 171-185, 2010.

[2] B. Lannoo, J. Van Ooteghem, D. Pareit, T. Van Leeuwen, D. Colle, I. Moerman, and P. Demeester, "Business model for broadband internet on the train," Journal of The Institute of Telecommunications Professionals, vol. 1, no. 1, pp. 19-27, 2007.

[3] T. Evens, D. Schuurman, L. D. Marez, and G. Verleye, "Forecasting broadband internet adoption on trains in belgium," Telematics and Informatics, vol. 27, no. 1, pp. $10-20,2010$.

[4] Eurescom. (2000) Project p901-pf extended investment analysis of telecommunication operator strategies. [Online]. Available: http://archive.eurescom.eu/ pub-deliverables/p900series/p901/D1/Vol2/p901d1vol2.pdf

[5] D. Pareit, E. Van de Velde, D. Naudts, J. Bergs, J. Keymeulen, I. De Baere, W. Van Brussel, C. Vangeneugden, P. Hauspie, G. De Vos et al., "A novel network architecture for train-to-wayside communication with quality of service over heterogeneous wireless networks," EURASIP Journal on Wireless Communications and Networking, vol. 2012, no. 1, pp. 1-30, 2012.

[6] H. Ghannoum and D. Sanz, "Internet onboard: Technical analysis," in Communication Technologies for Vehicles, 2013, vol. 7865, pp. 22-30.

[7] B. Naudts, J. Van Ooteghem, B. Lannoo, S. Verbrugge, D. Colle, and M. Pickavet, "On the right tracks? continuous broadband internet on trains," Journal of the Institute of Telecommunications Professionals, vol. 7, pp. 31-36, 2013. 